\title{
Health Promotion: Causes, Beliefs and Measurements
}

\author{
Robert D. Galloway, PhD, Southwest Texas State University, San Marcos, Texas
}

\section{REPRINT REQUESTS:}

Robert D. Galloway, PhD

Department of Health Administration

601 University Drive

San Marcos, TX 78666-4616

Telephone: 512-245-8239

Fax: 512-245-8712

Email: rg23@swt.edu

\section{KEYWORDS:}

Health promotion; Health behavior; Quality of life; Health status indicators; Health surveys; Attitude to health

RECEIVED:

MARCH 25, 2003

REVISED AND ACCEPTED:

JUNE APRIL 7, 2003

Clinical Medicine \& Research

Volume 1, Number 3: 249-258

○2003 Clinical Medicine \& Research

www.mfldclin.edu/clinmedres

\begin{abstract}
This investigative study summarizes the five most prevalent healthcare models and seven instruments to help the reader determine which model is the most effective in measuring health-related ideas and behaviors in subjects of varying populations. Their significance to the science and art of health promotion and analytical techniques are also reviewed. The purpose of the study is to consider varying arguments and apply them to abstractions of health promotion activities that readers may be contemplating.
\end{abstract}

\section{INTRODUCTION}

The United States healthcare system was developed through a series of historical accidents; with the idea that the employer or related party was the primary source of the healthcare benefit. ${ }^{1}$ Today's arrangement is the result of what organizations considered to be an appropriate solution to deal with the economic situation created by World War II. During World War II, employers began offering the incentive of health coverage to attract and retain scarce workers. In addition, employers of the 1940s in effect setup the current cultural expectation of health insurance. Health coverage essentially exists because businesses successfully lobbied Congress for a tax exemption for their compensation, which has created the expectation that healthcare be free. ${ }^{1}$

The United States healthcare system has been scrutinized over the past several decades because of concerns over rising costs, quality and inequitable access. ${ }^{2,3}$ Healthcare expenditures have continued to rise from approximately $\$ 73$ billion in 1970 , to an estimated $\$ 1,600$ billion in 2003 , and a projected $\$ 2,133$ billion 4 by the year 2007.

Those who control the system, that is, third party payors, physicians and the government, have proposed the majority of healthcare reform programs. Previous efforts to control healthcare costs have focused on the supply side (provider practice patterns, access, technology and inappropriate care) of the equation such as second opinions, early discharge, etc. Whereas demand management focuses on the other side of the equation, such as morbidity, perceived need, non-health motives and patient preference. ${ }^{5}$ 
The rise of Health Maintenance Organizations (HMOs) has been phenomenal. Perhaps the success of HMOs can be attributed to the elements of demand management that views healthcare management from the economic perspective of supply and demand. However, the promotion of HMOs has been under the guise of improved quality, greater costeffectiveness and improved access. ${ }^{6}$ These criteria allow individuals to observe the relationships between the success of HMOs and the factors identified to be contributors to the demand side. All are aggressively addressed in managed care environments, such as self-care and morbidity reduction, through morbidity and mortality risk modification.

Many employers offer a variety of health promotion services through the worksite. They have a vested interest since the employer still pays most of the healthcare expenses. ${ }^{7,8}$ Thus, employers are clutched in the healthcare grip. After more than a decade (late 1980s through the 1990s) of slowing healthcare costs and related premiums, organizations are once again having to address the issue of allocating more resources to provide employee health benefits. ${ }^{9,10}$ The combined trend of low inflation, positive economic conditions, the promise of cost control through the adoption of "managed care" measures, and the impact on healthcare cost control, is now beginning to reverse itself. ${ }^{11}$ From 1994 to 1998 these factors served to shield American workers and their families from rising healthcare costs. ${ }^{11}$

Insurance premiums have had annual increases ranging from $8.3 \%$ (Spring 2000) to $12.7 \%$ (Spring 2002), which stand in stark contrast to the $3.7 \%$ and $4.3 \%$ increases in the periods of 1997 to 1998 , and 1998 to 1999 respectively. $9,12,13$ The aforementioned shield is also disappearing as evidenced by trends that indicate an increase in employee contributions, deductibles and co-payments. It is anticipated that this cycle of double-digit increases will continue since claims expense, rather than the underwriting cycle is the major determinant of premium levels. ${ }^{13}$

Job sponsored insurance effects 16 million retirees, and 159 million workers and their families. Employer-based health insurance serves as a cornerstone of the United States economy. ${ }^{12}$

A healthcare concept that gained popularity in the 1980s was the creation of "wellness programs." Corporations in the United States eagerly adopted the concept of wellness programs in response to the desire to integrate healthy habits into the workplace. ${ }^{14}$ The National Survey of Worksite Health Promotion indicates that $66 \%$ of all worksites with more than 50 employees sponsor some type of health promotion. ${ }^{15}$ In addition to providing the impetus for employees to live healthier lifestyles, a second goal was to reduce employee healthcare costs through a reduction in the need to access acute medical care services. ${ }^{14}$

\section{FIVE THEORETICAL MODELS}

The greatest challenge in health promotion cost control measures is demonstrating the efficacy of interventions offered. Aside from an educational component, perhaps the greatest accomplishment in the health promotion arena is to effect in a positive direction, health behavior change or progress. Theoretical models have been explored in an attempt to articulate variables involved in health behavior to predict participation and engage would be non-participants. The following are brief summaries of five of the more prevalent models utilized. These summaries are provided to offer the reader insight into the conceptual dimensions applied in prudent practice settings.

\section{Health Belief Model (HBM)}

During the early 1950 s a variety of health screening (e.g., tuberculosis and pap smear) and preventive care services (e.g., immunizations, polio vaccine) were offered to the public for a nominal fee. Observers within the U.S. Public Health Service noted some persons did not participate in the services. Researchers sought to identify a framework to ascertain why a person would/would not participate in the desired health activity/behavior. ${ }^{16}$

Through their efforts, the Health Belief Model (HBM) was developed to examine client health behaviors. Two principle variables of HBM are the value of a health goal and the likelihood that the action will accomplish that goal. ${ }^{17}$ The map of the model can be viewed from three parameters:

- Modifying factors-identified as:

Demographics

(age, gender, race, ethnicity, etc.)

Sociopsychologic variables (social class, peer pressure, etc.)

Structural variables (knowledge about the disease, prior experience with the disease, etc.)

Cues to action (guidance from others, media advertisements, etc.)

- Individual perceptions-delineated as:

Perceived susceptibility (one's perceived risk for contracting a disease or illness)

Perceived severity (individual perceptions about the impact of the illness if contracted or left untreated [this might include the impact on family and work as well as the medical condition consequences of the process such as pain or disability])

Perceived threat (the individual's perception of degree of threat and the confidence that the desired action will affect that threat)

- Likelihood of action-described as:

Perceived benefits (the perceived effectiveness of the interventions)

Perceived barriers (the cost to the individual; convenience, time, pain, etc.) 
While generally accepted as a theoretical model of health behavior, upon closer review it does appear to be merely an articulation of variables potentially affecting behaviors. ${ }^{16} \mathrm{~A}$ review of forty-six studies which utilize the HBM as the health behavior framework examined the model from the standpoint of the sick-role behavior, clinic utilization and preventive health behaviors, through both prospective and retrospective examinations. ${ }^{17}$ The results were that perceived susceptibility was the strongest predictor for preventive health behaviors. The strongest predictor for sick-role behavior was the perceived benefits. The studies clearly support the HBM as a disease avoidance or disease protective model, as opposed to the eudemonistic appeal. ${ }^{16,17}$

\section{Health Promotion Model (HPM)}

The Health Promotion Model (HPM) categorizes the factors influencing behaviors similar to the HBM. Modifying factors, cognitive-perceptual factors and variables influencing the likelihood of action, are delineated. The HBM is a health protective model whereas the HPM is focused more on achievement of higher levels of well-being and self-actualization. ${ }^{16}$

- Modifying factors include behavioral and situational factors, interpersonal influences, and biological and demographic characteristics.

- Behavioral factors describe the person's prior experiences with a given activity. The activity and associated information previously learned may influence the person's selfefficacy in resuming participation in the activity.

- Situational factors may influence behavior as it relates to the surrounding environment. For example, if a person desires to lose weight, but only has high calorie or high fat food/meal options available they will be more challenged.

- Interpersonal influences relate to social support and expectations of others. A respected clinician that advises a client to quit smoking can provide the impetus for the client to quit. ${ }^{18}$ Families and work colleagues are other sources of encouragement or discouragement toward a change of behavior. ${ }^{7,19,20}$

- Age, gender, income, ethnic, racial and educational background comprises the demographic characteristics associated with the model. For example, as an individual's income increases there is a greater likelihood the participant will engage in preventive services. This aspect provides meshing of the HPM with the concept of self-actualization.

Basic needs must be met before the client aspires to higher levels of self-actualization. These modifying components are suggested to indirectly affect health behaviors; however, cognitive-perceptual factors are the "primary motivating mechanisms for acquisition and maintenance of health promoting behaviors."15
The cognitive-perceptual elements include items such as, importance of health and perceptions of control of health, self-efficacy, definition of health, health status, benefits of and barriers to health-promoting behaviors. ${ }^{16}$ The importance of health is clearly within the client's value scale; however, if health is not a priority or highly valued, the client may be less likely to act. It is at this juncture that a spiritual component could possibly be inferred given the definitions of spirituality and the relatedness to sense of purpose and values.

Different types of programs will be required for individuals with an internal versus external locus of control. The locus of control determines the individual's program expectations and outcomes. Externally controlled participants may not do well with an individual or self-directed program, and consequently require a group format. Research has demonstrated that locus of control can be accounted for by the perceived control of health, which directly relates to the client's confidence in their personal ability to accomplish the task. ${ }^{21}$

Another component of the HPM theory is cues. The cues to action are indirectly linked to the likelihood of action. Cues are more challenging to articulate and measure due to their subtle and complex nature; they may be from the media, environment, or be internally driven. Appointment reminder cards are an example of external cues that can help individuals who have an external locus of control. Internal cues, for individuals who have an internal locus of control, may be shortness of breath when walking up stairs or the exuberance felt after a mile of jogging once endorphins are released. ${ }^{16}$

Intensity of cues may vary depending on the level of readiness to act and locus of control of the participant. The individual perceptions and cognitive perceptual factors may describe interrelated systems or subsystems within which the individual lives and may influence their heath behaviors. It may well be that the intervention on controllable lifestyle factors will ultimately help avoid costs, improve functional outcomes for patients, and ultimately help improve patient functional outcomes.

Social Learning Theory (formerly known as Social Cognitive Theory) may also offer some insights for the cuing component of the HPM. Cognition refers to "the act or process of knowing including both awareness and judgment." 22 It is within this framework that the cognitive mechanisms of learning are stressed. The Social Learning Theory suggests "behavior, cognitive and other personal factors, and environmental influences all operate interactively as determinants of each other" while cognitive implies "a central knowing process in learning procedures," such that the theory "centers upon how people gain understandings of themselves and their environments and how they act in relation to those understandings." Almost all learning that results from direct experiences can occur by observing other individuals' 
behaviors and the consequences they must face for the choices they have made. This capacity to learn via observation gives individuals the opportunity to make rules for their behavior without having to perform their own trials and errors. $^{23}$

How the client defines health impacts their actions because it blends in with how they perceive their health status. A wide range exists between an individual that defines health as the absence of disease or symptom compared to someone who defines health as optimal physical function. This range between values is so wide that scales have been designed to measure this parameter. ${ }^{16}$ One can imagine, given the preceding definitions of health, that clients who define health so differently will report dissimilar health status when afflicted with the same condition. Just as patients vary in their definition of health, they also vary with the perceived benefit from completing an activity. Benefits can be both tangible and intangible. Some participants may receive tangible items (incentives) for involvement with a program or have a strong personal belief of intangible (better health) benefits. These same people may also have a strong affiliation with the concepts of perceived susceptibility. Barriers (or costs) can be perceived or real. Barriers may include the psychological component of negative messages countering their stated desire to participate, the convenience factor (again, a value issue), and/or a real barrier such as lack of facilities or programming.

\section{Transtheoretical Model (TTM)}

The Transtheoretical model was designed to describe behavior change mechanisms for smokers and can be best described from two dimensions. The first dimension, stages of change, is conceptualized by the "temporal, motivational, and constancy aspects of change" and operationalized as "precontemplation, contemplation, preparation (action) and maintenance." 24 The process of change is enumerated in the second dimension. The processes are characterized as helping relationships, consciousness raising, self-liberation, environmental reevaluation, counter-conditioning, reinforcement management, social liberation, stimulus control and dramatic relief. Synopses of the general assessment key for the stages of change are:

- Precontemplation - persons responding that they were not seriously considering quitting within the next six months.

- Contemplation - persons seriously considering quitting within the next six months, but not the next 30 days or had not made a quit attempt of 24 hours in the previous year or both.

- Preparation (action) - persons seriously considering quitting within the next six months, and planning to quit in the next 30 days, and had made a quit attempt of 24 hours in the previous year.

- Maintenance - maintaining the change or relapsing, at which point the client reverts to a previous stage of change.

\section{Theory of Reasoned Action (TRA)}

TRA has the cornerstone attribute of behavioral intention, which is the most important determinant of behavior. The "direct determinants of the individuals' behavioral intent are their attitudes toward performing the behavior and their social norm associated with the behavior." 25 The client's attitude is determined by their beliefs about the outcomes of performing the behavior measured against the assessment of the outcomes. Social norms are determined by the belief or support / non-support by important referents for performing the behavior compared against the motivation to comply with those referents.

\section{Diffusion Theory}

Conjecture of the methods of disseminating information (as it relates to health education from a public health perspective) through groups has been postulated through diffusion theory. ${ }^{26}$ It essentially suggests five elements of the population through which ideas/innovations occur: they are defined as innovators (those who become quickly interested in a new product, idea, or innovation), early adopters and early majority, the largest population element, (those who consider and then follow with adopting the activity, idea, etc.) and the late majority and late adopters (those who require the largest degree of prompting in order to engage in the idea, innovation, etc.).

Studies that overlay diffusion theory with social learning theory offer additional evidence of the prudence and efficacy of considering an eclectic theoretical approach. 27

\section{REVIEW OF THE LITERATURE OF HEALTH MEASUREMENTS}

The health promotion literature is replete with arguments from both proponents and adversaries as to the true costeffectiveness (and in some cases, cost-benefit) of health promotion activities.

Articles in professional journals, popular press and business literature generally support the concepts of health promotion. From the employer's standpoint, the interest lies in the outcome of the health promotion. Usually, measures of insurance claims, productivity, absenteeism and turnover are of the greatest concern. ${ }^{28-32}$ Others emphasize the specific cost-related issues. ${ }^{33-36}$

More recently, with the advent of managed care and the influence of total quality management, greater emphasis has been placed on outcomes and customer satisfaction as measures of effectiveness of interventions. Much of the focus has been on outcomes, particularly as they relate to function and health-related quality of life (HRQOL).

The challenges of measurement in health promotion practice prove to be just as exacting as those implicated in assessment of health systems. First, investigators must come to terms with an operational definition of health. Many cite the World Health Organization (WHO) definition of "health is 
not only the absence of infirmity and disease but also a state of physical, mental, and social well-being."37-39 The serious limitation to this definition is the absence of the spiritual parameter. 40,41

The significance of the issue is that the definition of health lays the groundwork for the building of health measures; it acts like a standard against which the validity of health measures should be judged. ${ }^{39}$ Health may further be described within the context of two dimensions: quality and quantity. The medical care system has historically focused on the quality parameter, with mortality having been the principle outcome guide for practice.

Avedis Donabedian, MD, MPH, dedicated his life to improving the quality of healthcare and healthcare systems. Donabedian wrote extensively about the issues of focusing on the quality parameter as it related to clinical practice and system impacts utilizing structure, process and outcome of frameworks. ${ }^{42}$ The importance of the quality of life parameter is the implication of the other social inputs that are inferred, such as housing, jobs, standards of living, etc. ${ }^{39}$ Donabedian further remarks that the conceptualization of health is broader and encompasses how healthy people function in everyday life and how they evaluate their own wellbeing.

Salient characteristics are two fold: the dimensions of health and the spectrum of health states from disease to wellbeing. 39 The five parameters for measurement include: physical health, mental health, everyday functioning in social and role activities, and general perceptions of wellbeing. Most scales for measurement address the negative or disease states with progress to identify those that could measure well-being. "A review of content should reveal items that focus on positive health states, e.g., well-being and vitality." 39 The parameters of interest and scales which are recommended are relevant to the population under study, and measures the goal sought. ${ }^{39}$ Similarly the "measurement of health status should be reserved primarily for assessments of ostensibly healthy people, usually in the context of aggregates of geographically defined population... of a service program." 38 Important parameters for measurements are recounted as "physical function, social function, emotional or mental status, burden of symptoms, and sense of wellbeing."38

Important considerations in the review of the dimensions for measurement are:39

- Physical-qualitative information solicited from the individual in accomplishing the task, i.e., two people may respond in the same manner to a question about the ability to perform certain physical activities with variance as to degree of suffering, etc.

- Mental health-to collect accurate information, clients should be queried directly about their feelings. Monitoring psychological well-being allows for greater understanding of the client's mental health along with including measures of cognition for assessment.
- Social functioning-these measures should not only note the number or frequency of contacts, but quality of the interaction.

- Role functioning-addresses role performances, i.e., school, work, employment (possibly self-care).

- General health-these should include measures for self-perceived well-being, energy, vitality, etc.

For application in the sphere of health promotion the important questions necessary to improve the efficacy of health promotion programs are as follows: ${ }^{37}$

- Is longevity increased?

- Is functioning enhanced?

- Is super-health achieved?

- Are there any ill effects of these programs?

According to Bergner,

To answer the first, assessment of survival or life expectancy is the best health indicator we have. To answer the other questions, the entire armamentarium of health status measure may be necessary... Presumably there are benefits of super-health... Estimation of benefits awaits precise definition and measurement of positive health. ${ }^{37}$

\section{INSTRUMENTS}

Seven devices for health measurement are examined below. These measurement devices include:

I. Health Risk Appraisal (HRA)

II. Health Enrollment Assessment Review (HEAR)

III. Health Promoting Lifestyle Profile (HPLP)

IV. Behavioral Risk Factor Surveillance System (BRFSS)

V. Medical Outcomes Study (MOS)36

VI. Wellness Evaluation Battery (WEB)

VII. Data Envelopment Analysis (DEA)

\section{Health Risk Appraisal (HRA)}

\section{DESCRIPTION AND INTENT OF THE HRA}

The HRA is an automated 84-item self-report lifestyle questionnaire with 6 biological parameters that target adults ages 18 to 65 . The lifestyle questionnaire is an assemblage of 3 separate components: a 10 year coronary heart disease mortality-health risk appraisal instrument from the Centers for Disease Control (CDC/HRA), a stress assessment scale (SAS), and the CAGE alcohol questionnaire: ${ }^{43}$

- Have you ever felt the need to Cut down on your drinking?

- Have you ever felt Annoyed by remarks about your drinking?

- Have you ever felt Guilty or remorseful about your drinking?

- Do you drink the first chance you get as an "Eye opener" to get going or calm down?

\section{CONCEPTUAL BASIS}

Lewis C. Robbins, M.D and Jack Hall, MD, introduced the HRA in 1970 in an effort to integrate prevention into clinical practice. Its purpose was to be "a procedure for 
using epidemiologic and vital statistics data to provide individuals with projection to their personalized mortality risk and with recommendation for reducing that risk, for the purpose of promoting desirable changes in health behavior."44

\section{FEASIBILITY OF INSTRUMENT UTILIZATION}

This is a self-report instrument; it assumes that the user reads and understands English and has the physical agility to use a writing implement to respond to questions. It is an automated software program, which would facilitate processing of reports. Scoring costs would be dependent on the volume and principally involve the time or person hours involved in scoring. It may be possible to prepare the tool for optical mark sensing if the computer route is preferred.

Time to complete the tool will vary from person to person dependent on reading and comprehension speed, setting or testing environment, and physical agility. Administration time will vary dependent on the sample. Some participants may need assistance with understanding working of the instrument.

\section{INSTRUMENT ACCEPTABILITY}

The HRA is not a clinically invasive tool; however, it may be considered intrusive to the extent that it solicits personal lifestyle information that is very sensitive. Fortunately, for the studies referenced for this paper, participants were ensured of anonymity. Unless the information will be reported and published as aggregated data, due to the sensitivity of the information participant confidentiality is imperative.

\section{Health Enrollment Assessment Review (HEAR) [Cost Risk Appraisal (CRA)] \\ DESCRIPTION AND INTENT OF THE HEAR}

The HEAR is a self-report questionnaire eliciting personal and family health history, utilization patterns, and self-perceived health status. This instrument was designed for the military managed care market; therefore, it is only for adult populations. Once the data is processed, the participant will receive their personal health report. As the client utilizes the medical care system the automation feature will also track the customer's system usage, thereby automating the Putting Prevention into Practice (PPIP) guidelines and the Health Plan Employer Data Information Set tracking requirements.

The development was commissioned by the United States Air Force to facilitate administration of managed care facilities. The intent of the instrument was actually to function as a cost risk appraisal. It is intended to identify high cost and high utilizers of medical care. It will also enable an automated method to optimize provider case-mix, and will additionally be used to monitor provider outcomes.

\section{CONCEPTUAL BASIS}

The HEAR was conceived to be a management tool. It is a powerful instrument that will incorporate the current stateof-the-art standards for delivering clinical preventive med- icine, such as U.S. Preventative Services Task Force, other certifying and credentialing bodies, and PPIP recommendations.

\section{INSTRUMENT ACCEPTABILITY}

The HEAR is an automated tool, which will expedite processing. Due to the nature of a large part of the instrument, it will not be useful in a community based setting.

\section{Health Promoting Lifestyle Profile (HLPP) \\ DESCRIPTION OF THE HPLP}

The HPLP is a copyright protected instrument that consists of a 48-item questionnaire scored by a 4-point summated rating scale. It consists of 6 subscales that include: self-actualization, health responsibility, exercise, stress management, interpersonal support and nutrition. ${ }^{45-47}$ These 6 subscales were derived from components of the HPM, which attempts to provide the framework for articulating health promotion lifestyles. The health promoting lifestyle is defined as "a multidimensional pattern of self-initiated actions and perceptions that serve to maintain or enhance the level of wellness, self-actualization and fulfillment of the individual."45 Because the test measures a wide rage of behaviors this instrument could be used in varying populations; when the researcher seeks to describe the health promoting lifestyle practices, the correlates or determents thereof, or measure results of interventions toward health promoting lifestyles. ${ }^{45}$ The instrument is scored from 1 to 4 with $1=$ never, $2=$ sometimes, $3=$ often, and $4=$ routinely. ${ }^{45-48}$ It is inferred that this instrument is intended for adults rather than a school age or pediatric population. This inference was drawn from a description of the sample populations in which the psychometric properties were established, as well as other studies that utilized this instrument, all of which only used adult samples. ${ }^{45-52}$

Further studies in other diverse populations examining samples with other states of health, ethnic background, and socioeconomic groups have been recommended in order to evaluate and enhance the validity of the instrument and establish population norms. ${ }^{45}$

\section{STATED INTENT OF THE TOOL}

The instrument is designed to "enable researchers to investigate patterns and determinants of health-promoting lifestyle, as well as the effects of interventions to alter lifestyle." 45 This is congruent with its intended use drawn from the conceptual basis of the HPM. Specific settings for instrument utilization are not enumerated. It would seem that just like the global health characteristics it seeks to measure, it may be applicable globally with some modification.

The HPLP was used in concert with other tools in the studies cited for this paper, and other instruments that are complementary to the HPLP, to provide a more comprehensive and corroborative perspective of the aggregates under study. 


\section{CONCEPTUAL BASIS}

The HPLP derives its roots from the concepts of the HPM. 53 While structurally similar to the perhaps better known HBM, which focuses on health-protecting behaviors, the HPM focuses on health promoting actions. The principle difference is that the HBM suggests that the behaviors are driven by desire for disease or illness avoidance, rather than the satisfaction or enjoyment that is posited as the underlying force in health promotion activities described in the HPM. ${ }^{53}$ This element of satisfaction as hypothesized in the HPM strongly integrates a self-actualization framework into the model. The HPM and HBM globally address complementary approaches in the complex conceptualization analysis of health related actions.

The HPM is best described as a paradigm of health behavior analysis consisting of two steps: decision-making and action. The decision making phase is influenced by cognitive perceptual and demographic factors. ${ }^{46}$ Cognitive perceptual factors include: importance and definition of health, and perceived control of health and health status, perceived benefits and barriers to the health promoting actions, and selfefficacy. Demographic elements include: age, gender, socioeconomic background, ethnicity and educational preparation. The "likelihood of engaging in health promoting behaviors" is step two. It is influenced by the modifying factors, cognitive-perceptual factors, and "cues" directly or indirectly. ${ }^{16,53}$

Since most health risk appraisals focus on disease prevention activities, this instrument was designed to attempt to provide information about health promoting lifestyle activities. Ideas for the HPLP were garnered from published sources that suggest "clusters" of activities that people perform for their own health purposes. The present HPLP is a self-report tool that participants scale to provide measures of six areas: self-actualization, nutrition, interpersonal support, exercise, health responsibility, and stress management. ${ }^{45}$

The designers of the HPLP instrument have linked the dynamics of the tool with the health promotion model. The HPM recognizes that health behaviors are multi-dimensional in their scope and effect.

\section{FEASIBILITY OF INSTRUMENTATION UTILIZATION}

Time to complete the tool will vary from person to person, dependent on reading and comprehension speed, setting or testing environment, and physical agility. Administration time will vary dependent on the sample. For example, large groups, elderly population, or samples that may require more explanation, may require more time for administrators to explain terminology or concepts. $.88,49,50$

\section{INSTRUMENT ACCEPTABILITY}

The HPLP is not a clinically invasive tool, however, due to the nature of the questions it may be considered intrusive to the extent that it solicits personal lifestyle information that is very sensitive. Unless the information utilized will be reported and published as aggregate data, due to the sensitivity of the information participant confidentiality is imperative when reporting data

The nature of the questions in the HPLP are not culturally offensive to Americans; however, certain items may require revision due to cultural variations in order to adapt the instrument for foreign applications or specific cultural groups.

\section{Behavioral Risk Factor Surveillance System (BRFSS) DESCRIPTION, INTENT, AND \\ CONCEPTUAL FRAMEWORK OF THE BRFSS}

National and statewide health information surveys are conducted by the Centers for Disease Control (CDC) and state health departments across the country. The hope was to gather information to measure progress toward Healthy People 2000 goals, the federal document outlining parameters or stands against which to measure population based health. With increasing emphasis for justifying effective resource utilization, additional questions were designed for the BRFSS to assess the HRQOL of respondents. This additionally functions as a measure toward the accomplishment of the goals set by Healthy People 2000 .

HRQOL is a multidimensional construct and includes the following parameters: physical function, psychological well being, social and role function, and health perception. ${ }^{54}$ Feasibility and ability to generalize the BRFSS and HRQOL constructs were developed with considerations for public and expert perspectives, public health policy focus, sensitivity to population variance, subjectivity versus objectivity, generic versus condition specific measures, cultural specificity, personal versus societal, reliability and validity, practicality, and time orientation.

\section{Medical Outcomes Study (MOS) 36 DESCRIPTION, INTENT, AND \\ CONCEPTUAL FRAMEWORK OF THE MOS 36}

The Medical Outcome Study (MOS 36) was a cross-sectional, 2 year, prospective study to assess the effects of provider attributes, preparation, interpersonal skills, practice patterns, resource utilization, and settings of care delivery on care outcomes. The intent was to identify those parameters associated with positive outcomes to enable maintenance of those facets of care as cost constrained environments grow. ${ }^{55}$ The MOS 36 is an instrument utilized in that study to assess responses to items that measure the client self reported physical, mental, and role-functioning; general health; and satisfaction. ${ }^{55}$

\section{Wellness Evaluation Battery (WEB)}

\section{DESCRIPTION AND INTENT OF THE WEB}

The WEB is a copyrighted, two-part survey instrument. Part one collects demographic data and data on over the counter medications, non-traditional health practices and behaviors, and data on health promotional services offered by the individual's employer. The second part of the survey is "WEB IT" where data is collected on individual heath 
related behaviors and life style behaviors. The WEB is intended to be used primarily in the work place as a mechanism to ascertain the efficiency of corporate sponsored wellness programs.

\section{CONCEPTUAL BASIS}

The WEB is intended to be a comprehensive survey document; collecting similar data as with the aforementioned instruments, but also collecting data on non conventional health practices and beliefs, and spirituality as it relates to healthcare. The instrument is intended to give individual feedback to participants, as well as give feedback to employers about the efficacy of the employee sponsored wellness program.

\section{FEASIBILITY OF INSTRUMENT UTILIZATION}

The WEB is a copyrighted, self-report instrument consisting of 138 questions comprising the two parts of the instrument. The WEB assumes that the user reads and understands English and has a basic knowledge of heath related terms. The WEB is a semi-automated instrument but still requires a limited amount of evaluation interpretation to record all of the data. For additional information or permission to use the WEB, contact the author.

\section{INSTRUMENT ACCEPTABILITY}

The WEB is not a clinically invasive tool, but it does solicit information on life style practices that some may find intrusive. Participants should be assured anonymity and only aggregate data should be reported.

\section{Analytical techniques}

Data envelopment analysis (DEA) and stochastic frontier estimation (SFE) are sophisticated mathematical analysis techniques that seek to identify the minimal cost mix of multiple inputs for a given output. ${ }^{57}$ In the healthcare setting they have principally been used to measure the efficiency of healthcare (nursing home and hospital) settings. If the establishment is determined to be inefficient, these techniques are able to identify and precisely define the magnitude of inefficiency. An innovative application for these measurement techniques was posited to attempt to measure health promotion dimensions, to determine the efficiency of the activities, and potentially articulate the least "cost" mix of inputs for any given output.

A variety of articles were reviewed that compared and contrasted the utilization of these methods in healthcare settings. When using DEA framework, one assumes no measurement error or random output variables: minimal error will not affect the demarcation of the frontier, but greater error margins would move the frontier and thereby affect the perceived inefficiency of concerns lying proximal to that area of the frontier. 57

SFE is an improvement on DEA, which makes the "distributional assumption of zero noise." SFE accounts for "noise" on the frontier, thereby giving a more realistic picture of efficiency and would therefore be preferred. 58 "All random noise in the DEA is lumped together with the true ineffi- ciency...the stochastic frontier model has the advantage of disentangling the two sources of error."57 While maximum likelihood estimators (MLE) were advocated by some, panel data techniques are suggested because "they require fewer distributional assumptions about the deterministic error." $58-60$ However, it should be noted that a panel estimator "must assume that the cost function and the extent of inefficiency... are constant over time," and that they may sometimes capture intangible "quality and amenity differentials." 61 Two other caveats are the concerns with aggregated measures producing measurement error and the assumption that the product produced is homogeneous. ${ }^{57}$ The question then becomes whether or not the health dimensions of interest should have these same noted abstractions applied and considered.

\section{SIGNIFICANCE TO THE SCIENCE AND ART OF HEALTH PROMOTION}

Most studies in the arena of health promotion have based their analyses on traditional methods cited in the healthcare literature using standard research methods such as: descriptive statistics (frequency distributions, correlation, etc.), inferential statistics (t-test, analysis of variance [ANOVA], chi-square, etc.), and advanced techniques (linear regression, analysis of covariance [ANCOVA], multivariate analysis of variance [MANOVA], etc.). This proposal offers a new and innovative means to evaluate health promotion activities and behaviors by precisely designating the degree of action further required to enter the defined health frontier.

This analysis is considered superior since it will establish the health frontier for any individual (or potentially, any aggregate, processes and inquiry with the characteristics of multiple inputs and outputs) and then identify how great the distance remaining to achieve optimal efficiency or determining the lowest cost mix to achieve the frontier health status.

\section{CONCLUSION}

With the ever increasing spiral of healthcare costs, health prevention seems like a sensible mechanism to both improve the health of the population while limiting, to some extent, the cost of healthcare. At this time however, as reasonable as healthcare promotions seem, there is little quantitative evidence to support their efficiency. This paper presents several models of healthcare promotion and several evaluation techniques and attempts to educate readers of which model and technique maybe best suited for varying situations.

\section{REFERENCES}

1. Kleinke, J.D. Bleeding the edge: the business of health care in the new century. Gaithersburg (MD): Aspen Publishers; 1998.

2. Yen, L.T., Edington, D.W., \& Witting, P. Corporate medical claim cost distributions and factors associated with high-cost status. J Occp Med 1994;36:505-515.

3. Standard \& Poor's Industry Surveys. New York: Standard \& Poor's; 1995, I38-I47. 
4. Department of Health and Human Services, Health Care Financing Administration, Office of the Actuary, 2002, Baltimore, MD.

5. Lynch, W.D. \& Vickery, D.M. The potential impact of health promotion on heath care utilization: an introduction to demand management. Am Health Promot 1993;8:87-92.

6. Findlay, S. Will big HMOs stamp out competition? Bus Health 1995:52-61.

7. Boyer, M.L. \& Vaccaro, V.A. The benefits of a physically active workforce: An organizational perspective. Occup Med 1990;5:691-706.

8. McCauley, M.J. \& Mirin, E. Employer sponsored health promotion: How to make it a family affair. Occup Med 1990;5:771787.

9. Gabel, Jon, Levitt, L., Pickreign, J., Witmore, H., Holve, E., Hawkins, S., and Miller, N. Job-based health insurance in 2000: premiums rise sharply while coverage grows. Health Aff (Millwood). 2000;19:144-151.

10. Baker, Lawrence C., Canton, J.C., Long, S.H., and Marquis, M.S. HMO market penetration and costs of employer sponsored health plans. Health Aff (Millwood) 2000;19:121-128.

11. Toner, Robin and Stolberg, S.G. Decade after health care crisis, soaring costs bring new strains. New York Times. August 11, 2003:Section 1, Page 1.

12. Gabel, Jon, Levitt, L., Holve, E., Pickreign, J., Whitmore, H., Dhont, K., Hawkins, S., and Rowland, D. Job-based health benefits in 2002: some important trends. Health Aff (Millwood) 2002;21:143-151.

13. Gabel, Jon, Levitt, L., Pickreign, J., Whitmore, H., Holve, E., Rowland, D., Dhont, K., and Hawkins, S. Job-based health insurance in 2001: inflation hits double digits, managed care retreats. Health Aff (Millwood) 2001;20:180-186.

14. Sullivan, Bernard J. New wellness programs can produce big savings. Baltimore Business Journal 1997;15:26-27.

15. Stead, Bette Ann. Worksite health programs: a significant costcutting approach. Business Horizons 1994;37:73-79.

16. Pender, N.J. Health Promotion in Nursing Practice (2nd ed.). Norwalk: Appleton \& Lange; 1987.

17. Janz, N.K. \& Becker, M.H. The health belief model: A decade later Health Educ Q. 1984 Spring;11:1-47.

18. Counseling practices of primary-care physicians, August 7, 1992. MMWR 1992;41;565-568.

19. Mermelstein, R., Cohen, S., Lichtenstein, E., Baer, J.S., \& Kamarck, T. Social support and smoking cessation and maintenance. J Consult Clin Psychol 1986;54:447-53.

20. Robbins, S.B. \& Slavin, L.A. A measure of social support for health related behavior change. Health Education 1988:3639.

21. Wallston, B.S., Wallston, K.A., Kaplan, G.D., \& Maides, S.A. Development and validation of the health locus of control (HLC) scale. J Consult Clin Psychol 1976;44:580-5.

22. Webster's Seventh New Collegiate Dictionary. Springfield: G\&C Merriam Co; 1971.

23. Bigge, M.L. \& Shermis, S.S. What is the cognitive-field interactionist theory. Learning Theory for Teachers (5th ed.). New York: Harper Collins; 1992.

24. DiClemente, C.C., Prochaska, J.O., Fairhurst, S.K., Velicer, W.F., Velasquez, M.M., \& Rossi, J.S. The process of smoking cessation: An analysis of precontemplation, contemplation, and preparation stages of change. J Consult Clin Psychol. 1991;59:295-304.

25. Montano, D., Kasprzyk, D., Taplin, S. The Theory of Reasoned Action and the Theory of Planned Behavior. In Glanz, K., Lewis, F., Rimer, B., Health Behavior and Health Education: Theory, Research and Practice. San Francisco: Jossey Bass, 1995: page 55-101.
26. Dignan, M., Tillgren, P., \& Michielutte, R. Developing process evaluation for community based health education research and practice: A role for the diffusion model. Health Values 1994;18:56-59.

27. Clarr, N.M., Zimmerman, B.J., A social cognitive view of selfregulated learning about health. Health Educ Res 1990;5:371.

28. Shepard, R., Corey, P., Ruezland, P., \& Cox, M. Can J Public Health 1982;73:259-262.

29. Bernacki, E. \& Baun, W. The relationship of job performance to exercise adherence in a cooperate fitness program. $\mathrm{J}$ Occup Med 1984 Jul;26:529-531.

30. Bertera, R.L. The effects of behavioral risks on absenteeism and healthcare costs in the workplace. J Occup Med 1991;33:1119-1124.

31. Lynch, W., Golaszewski, T., Clearie, A., Snow, D., \& Vickery, D. Impact of a facility-based corporate fitness program on the number of absences from work due to illness. J Occup Med 1990;32:9-12.

32. Tsai, S., Bernacki, E., \& Baun, W. Relationship of employee turnover to exercise adherence in a corporate fitness program. J Occup Med 1987;29:572-575.

33. Pelletier, K. A review and analysis of the health and cost-effective outcome studies of comprehensive health promotion and disease prevention programs at the worksite: 1991-1993 Update". Am J Health Promot 1993;8:50-62.

34. Gorsky, R.D. \& Teutsch, S.M. Assessing the effectiveness of disease and injury prevention programs: cost and consequences. Morb \& Mortal Wkly Rep 1995;44:1-10.

35. Bertera, R. Behavioral risk factors and illness day changes with workplace health promotion. Am J Health Promot 1993:7:365-373.

36. Kingery, P.M., Ellsworth, C.G., Corbett, B.S., Bowden, R.G., Brizzolara, J.A. High cost analysis, a closer look at the case for work-site health promotion. J Occup Med 1994;36:13411347.

37. Bergner, M. Measurement of health status. Med Care 1985:23:696-704.

38. Spitzer, W.O. State of Science 1986: Quality of life and functional status as target variables for research. J Chronic Dis 1987; 40:465-471.

39. Ware, J.E. Standards for validating health measures: Definition and content. J Chronic Dis 1987;40:473-480.

40. Hawks, S.R., Hull, M.L., Thalman, R.L., \& Richins, P.M. Review of spiritual health: definition role, and intervention strategies in health promotion. Am J Health Promot 1995;9:371-378.

41. Gray, Paula. Health Promotion: exploring a new frontier. Unpublished paper: University of the Incarnate Word; 1995; San Antonio, Texas.

42. Donabedian, A. The Definition of Quality and Approaches to its Assessment. Ann Arbor: Health Administration Press; 1980.

43. Kick, SD, Evaluation and Management of Chronic Alcohol Abuse. Available at: http://www.hosppract.com/issues/1990/04/cekick.htm. Accessed on June 1, 2003.

44. Gemson, D.H., \& Sloan, R.P. Efficacy of computerized health risk appraisal as part of a periodic health examination at the worksite. Am J Health Promot 1995;9:462-466.

45. Walker, S.N., Sechrist, K.R., \& Pender, N.J. The health-promoting lifestyle profile: Development and psychometric characteristics. Nurs Res 1987;36:76-81.

46. Gillis, A., \& Perry, A. The relationships between physical activity and health-promoting behaviors in mid-life women. JAdv Nurs 1991;16:299-310.

47. Duffy, M.E. Determinants of health-promoting lifestyles in older persons. Image J Nurs Sch 1993;25:23-28.

48. Foster, M.F. Health promotion and life satisfaction in elderly black adults. West J Nurs Res 1992;14:444-456. 
49. Weitzel, M.H. A test of the health promotion model with blue collar workers. Nurs Res 1989;38:99-104.

50. Walker, S.M., Kerr, M.J., Pender, N.J., \& Sechrist, K.R. Spanish language version of the health-promoting lifestyle profile. Nurs Res 1990;39:268-273.

51. Pender, N.J., Walker, S.N., Sechrist, K.R., Frank-Stromborg, M. Predicting health-promoting lifestyles in the workplace. Nurs Res 1990;39:326-332.

52. Kuster, A.E. \& Fong, C.M. Further psychometric evaluation of the Spanish language health-promoting lifestyle profile. Nurs Res 1993;42:266-9.

53. Pender, N.J. Health Promotion in Nursing Practice. Norwalk: Appleton \& Lange; 1982.

54. Henessey, C.H., Moriarty, D.G., Zack, M.M., Scherr, P.A., \& Brackbill, R. Measuring the health-related quality of life for public health surveillance. Public Health Rep 1994;109:665671.

55. Tarlov, A.R., Ware, J.E., Greenfield, S., Nelson, E.C., Perrin, E., \& Zubkoff, M. The medical outcomes study: An application of methods for monitoring the results of medical care. JAMA 1989 Aug 18;262:925-930.

56. Nelson, E.C., Batalden, P.B., Plume, S.K., Mihevc, N.T., \& Swartz, W.G. Report cards or instrument panels: who needs what? Jt Comm J Qual Improv 1995;21: 115-166.

57. Newhouse, J. Frontier estimation: How useful a tool for health economics? J Health Econ 1994;13:317-322.

58. Vitaliano, D.F. \& Toren, M. Frontier analysis: A reply to Skinner, Dor, and Newhouse. J Health Econ. 1994;13:317322.

59. Dor, A. Non-minimum cost functions and the stochastic frontier: On applications to health care providers. J Health Econ 1994;13:329-334.

60. Zuckerman, S., Hadley, J., \& Iezzoni, L. Measuring hospital efficiency with frontier cost functions. J Health Econ 1994;13:255-280.

61. Hadley, J. \& Zuckerman, S. The role of efficiency measurement in hospital rate setting. J Health Econ 1994;13:335-340. 